\title{
Redes de associações de grupos camponeses na Amazônia Oriental (Brasil): fontes de capital social?
}

\author{
Maria Cristina Maneschy - Universidade Federal do Pará, Brasil \\ Alden Klovdahl - Australian National University, Austrália ${ }^{1}$
}

\section{Resumo}

$\mathrm{Na}$ Amazônia Oriental, tem crescido o número de associações de grupos camponeses, especialmente a partir dos anos noventa do século passado. Elas buscam meios alternativos para lidar com interesses comuns e organizar esforços individuais e coletivos e, desse modo, contribuir com a redução das desigualdades. Este estudo baseia-se em dados de entrevistas com líderes de trinta e seis associações rurais em três municípios do nordeste do Estado do Pará. Examina em que medida essas organizações representavam formas de capital social, isto é, redes capazes de produzir e prover acesso a recursos do ponto de vista dos grupos locais. O ambiente dessas redes é analisado, enfatizando-se os conjuntos de relações que mantinham com associações similares, ONGs, instituições governamentais, movimentos sociais, sindicatos e políticos. Se dispor de conexões sociais era fator crucial para as associações alcançarem os objetivos imediatos, constatou-se que elas não eram em geral suficientes para se sobreporem às restrições dos contextos. Barreiras concretas à comunicação reduziam a habilidade da rede em difundir os recursos imersos ou acessíveis.

Palavras-chave: associações camponesas; capital social; ambiente de rede; Amazônia.

\begin{abstract}
In the northeastern Amazon region of Brazil there has been a notable proliferation of peasants' associations, particularly from the 1990s. They aim to provide alternative means to deal with common interests and to organize individual and group efforts, thus contributing to reduced inequalities. This study draws on interviews with leaders of thirty-six rural associations in three municipalities in the State of Pará. The paper considers the extent to which these local organizations represented forms of social capital, that is, social networks able to produce and to provide access to valued resources. The network environment of the associations is examined, with particular reference to their external links with similar associations, NGOs, government institutions, social movements, unions and politicians. Social connections appeared significant for the goals of the associations. Nevertheless, concrete barriers to communication reduced the network ability to spread the resources embedded or accessible.
\end{abstract}

Keywords: peasants' associations; social capital; network environment; Amazonian region.

\footnotetext{
${ }^{1}$ Enviar correspondencia a: maria.maneschy@pesquisador.cnpq.br
} 


\section{I ntrodução}

Na Amazônia Oriental, onde o campesinato se destaca como força social, econômica e política assiste-se, desde a última década, a uma notável proliferação de associações rurais, sob diferentes denominações. São associações de pescadoras, pescadores, agricultores, agricultoras, quilombolas, grupos de artesãs, moradores em unidades de conservação, comunidades indígenas, dentre outras, que visam fortalecer os grupos na defesa de seus meios de vida e na obtenção de recursos de diferentes ordens. Elas surgem em geral estimuladas por programas públicos de crédito e assistência técnica, de acesso ao território, de formação profissional, ou de alocação de serviços públicos. Essa movimentação suscitou o interesse de investigar a contribuição dessas organizações locais na superação das desigualdades sociais, em âmbito local ou mais abrangente e na promoção de democracia participativa. ${ }^{2}$

Dentro de uma perspectiva teórica do capital social como recursos imersos em redes de relações sociais, formulou-se a hipótese de que a força das associações rurais repousaria em parte nos laços sociais dos membros entre si e, especialmente, com outras organizações, pessoas e instituições, contornando barreiras locais e caminhos pré-traçados de acesso a recursos por meio de laços de dependência clientelística. As associações foram então tomadas como elementos de conjuntos de grupos, instituições e organizações, em âmbito local e extra local, conforme a abordagem sociológica de redes sociais, buscando-se as implicações de sua posição nesses conjuntos.

Este artigo baseia-se em entrevistas com líderes de trinta e seis associações em três municípios do nordeste do Estado do Pará, realizadas no primeiro semestre de 2005. O foco da presente análise é o conjunto de relações externas que tais associações mantinham. Indaga-se em que medida tais relações constituíam fontes de capital social para as comunidades rurais, tanto no sentido de propiciarem acesso a recursos quanto de diversificarem - e inovarem - os modos de acesso. A análise dos padrões estruturais das redes foi feita com o apoio de Netdraw, via software Ucinet (Borgatti, Everett and Freeman, 2002), complementado por análise qualitativa das percepções dos líderes sobre as interações.

\footnotetext{
2 Esse é o objeto do Projeto “Estudo sobre Associações Rurais e Participação Política na Amazônia Oriental - EPAR", apoiado pelo CNPQ e Programa PROINT/UFPA, em execução a partir de 2005.
} 


\section{Redes e capital social}

Argumenta-se, aqui, sobre o interesse do conceito de capital social, notabilizado por Putnam (2002) e Lin (2001) e, antes deles, por Bourdieu (1986) e Coleman (1998), que se refere ao potencial das redes sociais gerarem solidariedades e reciprocidades e, portanto, de se constituírem em recursos sociais apropriáveis pelas pessoas e coletividades que interagem em rede. Nesse campo, destaca-se também o enfoque de Granovetter (2004) quanto à imersão da ação social em "sistemas concretos e continuados de relações sociais", isto é, em redes de relações, das quais derivam confiança, controle e ganhos diversos. Seu conhecido estudo sobre busca de empregos e recrutamento (1974) detectara a "força" dos contatos de uma pessoa no seu acesso ao mercado de trabalho.

O conceito de capital social refere-se, pois, a capacidades inscritas nas conexões sociais, que concorrem para a ação comum e para a consecução de benefícios. Tornam possível alcançar determinados fins inatingíveis por indivíduos isolados, se contassem unicamente com seus atributos pessoais, posição de classe ou status. Este aspecto foi ressaltado, dentre outros, por Fontes e Eichner (2004) ao examinarem redes pessoais de moradores em bairros periféricos de uma cidade no nordeste brasileiro.

Parte da literatura aponta, ademais, para a possibilidade de que recursos sociais eficazes localmente o sejam também para sustentar ações coletivas de maior impacto, capazes de influenciar no plano político em prol dos grupos articulados. Sabe-se por outro lado, como acentuam diversos autores, que tal abordagem é inconsistente se não se levam em conta os contextos históricos e sociais nos quais se constrói a participação e, em particular, sem que se considerem as desigualdades sociais e políticas e seus efeitos sobre as redes sociais (Portes, 1998; Woolcock e Narayan, 2000; Beall, 2001; Kerstenetzky, 2003; Cleaver, 2005; Theiss-Morse e Hibbing, 2005).

A influência dos contextos sócio-históricos na conformação das redes foi especialmente ressaltada por Murdoch (2000) ao discutir as relações entre redes sociais e promoção de desenvolvimento em áreas rurais. Ele examinou a literatura sobre regiões agro-industriais prósperas em diferentes países, marcadas por redes horizontais de pequenos e médios empreendimentos, em arranjos produtivos flexíveis e favoráveis a "aprendizado e inovação"; elas comumente se tinham 
constituído a partir de práticas de cooperação e confiança estabelecidas entre famílias residentes de longa data em áreas rurais. Precisamente esse estoque de capital social anterior, nos termos de Putnam (2005), fornecera as bases para que as unidades produtivas locais se adaptassem e inovassem em resposta a transformações cruciais nos mercados.

Assim, destacou o autor, recursos locais herdados podem promover formas de organização apropriadas aos imperativos da "economia em rede" globalizada, conforme a acepção de Castells (2000), desde que flexíveis e diversificados de modo a favorecer aprendizado conjunto, transferência de conhecimento e adaptabilidade a mudanças (Murdoch, 2000). Porém, adverte o autor, a relativa excepcionalidade de tais regiões, a existência de áreas de produção inseridas em redes verticais, a exemplo das cadeias de commodities, ou aquelas enfraquecidas por padrões anteriores de desenvolvimento, indicam que diferentes tipos de redes interagem de maneira diversa com as condições preexistentes. Elas reclamam, pois, estratégias de desenvolvimento diferenciadas, com distintas formas de intervenção estatal (Murdoch, 2000).

A esse respeito, vale mencionar a análise de Lima (2001) sobre uma experiência de política pública participativa de geração de emprego e renda no nordeste brasileiro. Tratava-se do estímulo à formação de cooperativas artesanais para abastecer plantas industriais. A falta de transparência quanto aos termos do acordo para o conjunto de atores envolvidos, mostrou o autor, fez com que a iniciativa de formar uma cadeia produtiva aparecesse aos cooperados como simples oferta de mão-deobra barata para empresas. Não se constituíra a confiança que sustentaria o empreendimento. Lima (2001) chamou a atenção para a necessidade da presença continuada de instituições do poder público, clareza de normas e, em especial, mecanismos de comunicação nos esforços para desenvolver arranjos produtivos horizontais entre parceiros desiguais em poder e recursos.

Em suma, os enfoques das redes como fontes de capital social, como ativos relacionais, apontam para duas dimensões de análise. De um lado, as potencialidades inerentes à estrutura das relações sociais, que facilitam as ações: reciprocidades, confiança, normas e recursos partilhados. E, de outro, a posição das redes locais e de seus elos nas estruturas de redes mais amplas em que necessariamente se inserem. Redes sociais se formam e operam de maneira dinâmica, na interseção entre influências internas e do ambiente externo. 


\section{Associações rurais na Amazônia: flexibilidade e necessidade}

A despeito da falta de registros unificados sobre associações rurais, que são em princípio organizações de adesão voluntária, muitas são as evidências de sua expressão numérica. A Federação dos Trabalhadores na Agricultura do Estado do Pará mantinha em seus arquivos em janeiro de 2005, os estatutos de pouco mais de duzentas associações. Por sua vez o SINE-PARÁ (2004), em diagnóstico sobre a pesca artesanal no Pará, identificou sessenta associações em localidades pesqueiras, sendo onze de mulheres.

Associações locais de grupos camponeses são alvos de políticas e de agências de desenvolvimento. Isso é compreensível em uma região na qual a população rural é bem superior à média nacional - 30\% e 18\% da população total, respectivamente - e onde faltam oportunidades de inserção no setor formal da economia para amplos contingentes populacionais, tanto urbanos quanto rurais. Ademais, seguindo uma tendência internacional nos discursos sobre desenvolvimento e meio ambiente, sublinha-se o valor de promover, ao lado de uma presença estatal efetiva no vasto território amazônico, o respeito pelas diferenças, a participação da sociedade e as "associações que contribuam para formar capital social" (BRASIL, 2004).

Há associações que derivam de mobilizações anteriores, como as situadas em assentamentos de reforma agrária e em unidades de conservação ambiental chamadas "reservas extrativistas", que são reservas que devem assegurar os direitos dos moradores e usuários tradicionais dos recursos naturais da área (Hébette, 2002; Moreira, 2002; Medeiros e Leite, 1999). Nesse caso situam-se, também, as associações em comunidades quilombolas, isto é, comunidades que tiveram reconhecido o seu estatuto de remanescentes de povoações fundadas por antigos escravos fugidos. ${ }^{3}$ As associações rurais também surgiram, principalmente, por indução de programas de financiamento ou crédito para atividades econômicas, como o Fundo Constitucional do Norte - FNO e o Programa Nacional de Fortalecimento da Agricultura Familiar - PRONAF (Tura, 2002), que condicionavam o atendimento ao fato de os beneficiários estarem reunidos em associações.

\footnotetext{
${ }^{3}$ Processos de reconhecimento de territórios quilombolas passaram a ocorrer no Brasil especialmente a partir da década passada.
} 
Por seu turno, associações são organizações flexíveis se comparadas à filiação sindical, que é obrigatória para o acesso à seguridade social e restringe-se às categorias profissionais reconhecidas: os Sindicatos de Trabalhadores Rurais e as Colônias de Pescadores. Dentre as associações estudadas, há agrupamentos segundo critérios diversos da identificação profissional formal, o que sugere um maior encaixamento nas condições de vida locais. Com sua variedade de denominações, elas podem estar apontando que as comunidades locais dependem das atividades realizadas pelo conjunto dos membros, dos trabalhos das mulheres e dos homens, de crianças e adultos, em diferentes áreas. Teriam elas, assim, potencial para expressar os interesses que decorrem das condições concretas de vida e das formas de inserção no tecido social? Essa dimensão diz respeito à qualidade das relações sociais que conformam processos de transição democrática substantiva, como ressaltaram Avritzer (1997) e Costa (1999).

A par desse dinamismo, as associações rurais coexistem e podem até reforçar antigas práticas de controle social. Como aponta a literatura sobre a temática, associações locais podem forjar grupos auto-centrados que, na busca de seus interesses particulares e imediatos, enfrentando as carências resultantes das restrições do Estado em fornecer bens e serviços sociais, terminam por alijar-se das questões políticas de abrangência maior. Além disso, podem fragmentar a representação das categorias, ainda que sob um aparente processo de constituição de atores sociais e de fortalecimento da sociedade civil (D'Incao, 2000).

Neste sentido, seriam as associações capazes de influir sobre tendências dominantes de exclusão social, de diversificar a agenda das organizações sindicais, de fertilizar a discussão pública e de interferir nas ações estatais? Quais seriam os fatores capazes de fortalecer tais dimensões positivas? Uma das respostas reside, certamente, na inserção das associações em grupos e intercâmbios de organizações capazes de vincular as demandas locais a ações e mobilizações mais amplas. A estrutura dessas relações também importa. Em que direções fluem os recursos e como se distribuem? São aspectos relevantes para se compreender em que medida representam capital social, isto é, fontes de poder para os grupos locais.

Na formação dessas associações locais conjugam-se, pois, fatores de flexibilidade e fatores impositivos da forma associativa, especialmente como via para obter informação, financiamentos, bens e serviços e participar da gestão dos territórios. Em suma, recursos absolutamente necessários para aqueles que estavam assumindo os riscos e os custos nada desprezíveis de se associar. 


\section{Procedimentos metodológicos}

Este estudo enfoca as associações rurais enquanto inseridas em redes sociais, examinando-se a composição de seus elos e a acessibilidade aos eventuais recursos imersos. Os dados foram obtidos via entrevistas semi-diretivas com os líderes de trinta e seis associações em três municípios do nordeste do Pará em que a pesca artesanal e a agricultura familiar sobressaem na economia, e pretenderam compor um primeiro perfil desse "fenômeno associativo" em expansão na região. As entrevistas foram gravadas. Em caráter complementar, nas sedes dos municípios, levantaram-se informações junto a agências de extensão rural, sindicatos e secretarias de agricultura e pesca.

As entrevistas com os líderes visaram a história da associação, os grupos envolvidos e seus motivos, os fatores que levaram à criação, as ações em curso e as agendadas, além de solicitarem do informante uma avaliação sobre conquistas e problemas. E, evidentemente, o objeto da presente análise: a identificação dos contatos, isto é, com quem a associação interagia direta ou indiretamente e o tipo de interação; esses dados permitiram elaborar os gráficos das redes com o uso do programa Netdraw, discutidos adiante.

Para os conteúdos das interações, indagou-se sobre a existência de acordo ou contrato com algum órgão para repasse de bens, meios financeiros ou serviços (por exemplo, cursos); fontes e tipos de apoio recebidos e prestados, entendendo-se por apoio desde empréstimos, doações financeiras, cessão de materiais, transporte, serviços, até encorajamento, conselho, companhia em viagem, informação, redação do estatuto da associação e intermediação para um contato relevante. É preciso notar que questões assim formuladas geralmente são limitadas para captar relações e práticas informais e ocasionais. Por isso, quaisquer referências que o entrevistado fazia a contatos de qualquer natureza, inclusive em resposta a outros tipos de questões, foram computadas, independente da freqüência ou intensidade das relações.

No tratamento dos dados, os tipos de contatos foram sistematizados nas seguintes categorias: prestação de favor, crédito, atividades de formação, assistência técnica, informação, cessão ou viabilização de acesso a equipamento, participação em reuniões e encontros e, finalmente, serviços relacionados a bem estar social, a exemplo do transporte de alguma pessoa doente. Essa classificação apresentou algumas lacunas pela dificuldade de enquadrar com precisão as ações pertinentes e, portanto, torná-las todas passíveis de tratamento quantitativo. 
O fato de não ter sido possível observar uma associação funcionando, assistir a reuniões ou acompanhar as rotinas representou uma limitação metodológica da pesquisa. Outra, a possibilidade de nem todos os contatos terem sido enumerados e seus conteúdos e direção explicitados. Estima-se que essas restrições foram parcialmente contornadas com a profundidade das entrevistas e o conseqüente registro das conexões mais significativas do ponto de vista dos informantes.

\section{As associações e seus contatos}

As trinta e seis associações, juntamente com seus contatos, formavam uma rede de cento e doze 'nós'. A Figura 1 representa essa rede, sem distinção por tipos de contatos. As associações se relacionavam com orgãos governamentais, ONGs, movimentos sociais, sindicatos e algumas categorias de pessoas. Destacavam-se no conjunto os bancos oficiais e a agência de extensão rural que operavam o crédito rural subsidiado - os dois maiores círculos ao centro - o que se explica por ser esse o objetivo imediato da quase totalidade das associações. ${ }^{4}$ Nota-se também na parte central da figura, além das associações de agricultores (quadrados) e de pescadores (losangos) predominantes na amostra, os políticos (círculo branco envolvido por quadrado) e as entidades sindicais (círculos em cinza, de tamanho médio).

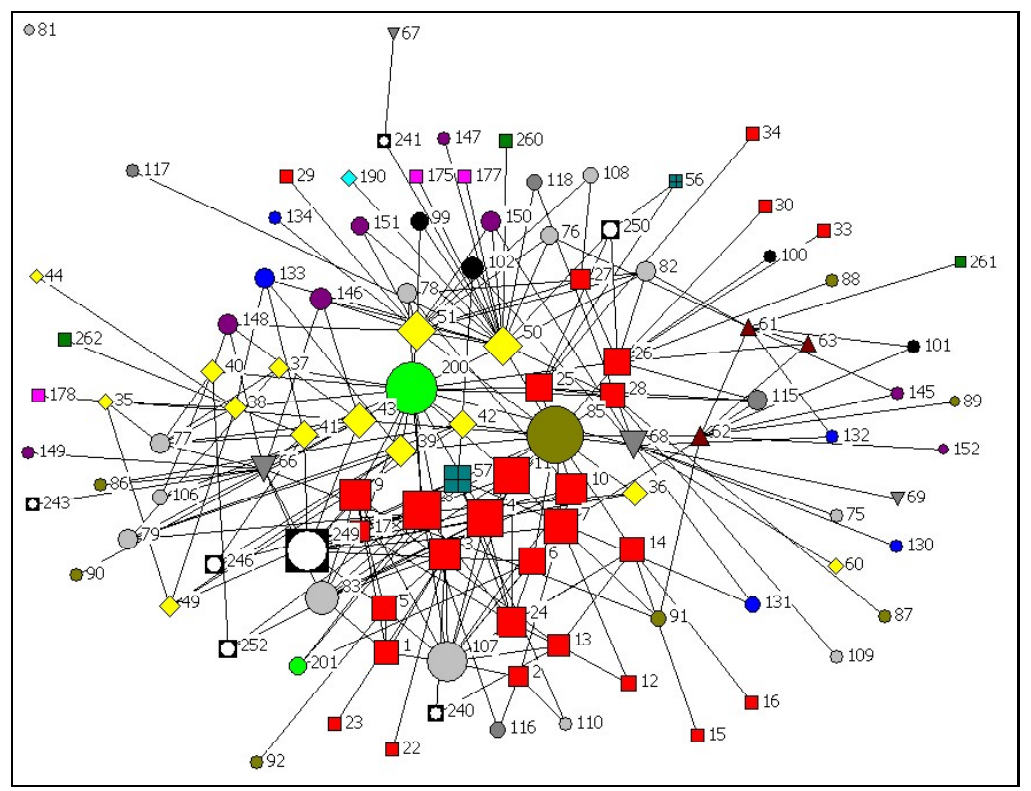

\footnotetext{
${ }^{4}$ Banco da Amazônia, Banco do Brasil e EMATER, esta última a agência estadual que atua na formulação e acompanhamento dos planos de crédito rural para pequenos produtores.
} 
Figura 1. Rede de contatos de trinta e seis associações rurais em três municípios do nordeste do Estado do Pará (2005)

Chama atenção a quantidade de pequenos nós nas extremidades, que se referem basicamente a dois tipos: as associações com reduzido número de contatos e a miríade de instituições e organizações apontadas por poucas associações locais, o que explica as posições periféricas na rede.

Portanto, as associações diferiam sensivelmente nos seus padrões de contatos. Isso era evidente, de um lado, pelo número de laços diretos que mantinham (ego networks) e, de outro, por sua posição na estrutura da rede mais ampla. As associações distinguiam-se em três grupos segundo o número de ligações diretas: um terço (doze) exibia oito e mais contatos, metade (dezoito associações) cinco a sete contatos e, finalmente, um pequeno grupo de seis associações com um a três contatos. Essas diferenças não se relacionavam com a idade da associação.

Tendo em vista que as associações buscavam recursos não disponíveis nas localidades, a diversidade dos contatos era em princípio uma condição favorável. As três associações em comunidades quilombolas e as três em áreas de reservas extrativistas ou em sua zona de influência destacavam-se de longe no quesito número e diversidade de contatos. Elas interagiam com ONGs de defesa de negros, dos direitos dos quilombolas, de apoio a "populações tradicionais" amazônicas, ambientalistas, de educação popular, de mulheres etc... Seus contatos envolviam, ainda, órgãos públicos estaduais e federais, inclusive instituições de pesquisa. Com efeito, trata-se aqui de categorias sociais e de questões que passaram a atrair grande interesse no país, sobretudo desde a última década (Esterci, Lima e Lena, 2002). Isso se traduz em programas específicos de formação, pesquisa, crédito e regularização fundiária. A Figura 2 ilustra esse perfil de contatos variados. As quilombolas são expressas como triângulos à direita da figura. Note-se, na parte inferior esquerda, uma associação de mulheres (triângulo invertido) em uma comunidade pesqueira inscrita na reserva extrativista, que se tinham organizado para se beneficiarem de programas de formação e de geração de renda para os moradores. 


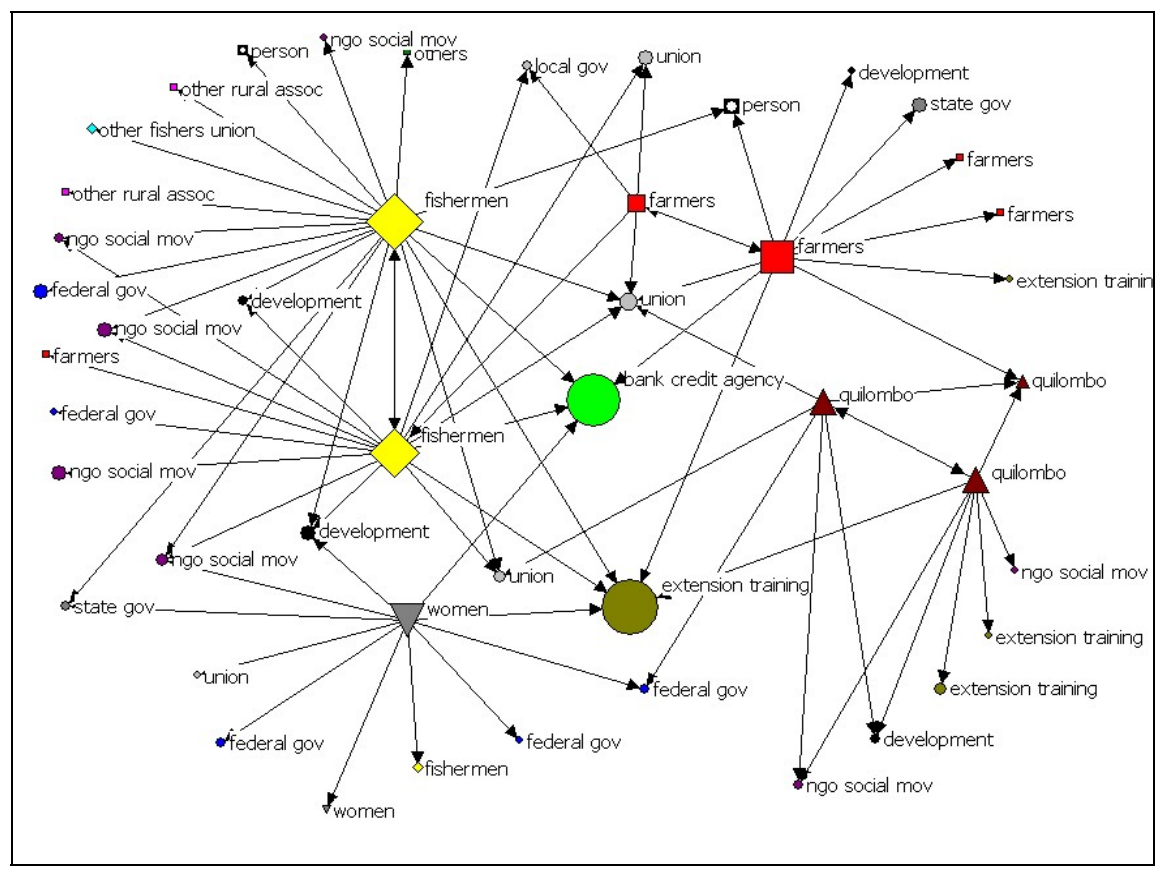

Figura 2. Contatos diretos de associações em comunidades quilombolas e em área de reserva extrativista e seu entorno, no nordeste paraense (2005)

Em contrapartida, a maior parte das associações de pescadores e agricultores exibia um menor rol de contatos, mais homogêneos e restritos ao nível local, salvo para as situadas na área de influência daqueles territórios especiais e aquelas cuja trajetória vinculava-se à atuação de movimentos sociais, especialmente ligados a igrejas e a questões de reforma agrária. Para a maioria, os principais contatos eram, em primeiro lugar, os bancos e a agência oficial de assistência técnica e, em segundo lugar, com grande expressão, os políticos, tanto eleitos quanto candidatos, que procuravam a associação ou eram por ela procurados para solucionar problemas e encaminhar demandas. Em seguida, vinham os órgãos sindicais, nos níveis municipal e estadual.

A análise quantitativa e formal dos contatos deve ser, evidentemente, seguida da análise qualitativa do conteúdo das relações, dos processos de comunicação que se estabelecem, dos recursos que fluem e em que direções. Contudo, esse primeiro dado chama a atenção para a variedade de ações coletivas locais sob a forma institucional das associações, que os entrevistados quase unanimemente consideravam uma condição sine qua non para serem "vistos" ou "ouvidos". Alem disso, eram obrigatórias para agricultores familiares e pescadores artesanais pleitearem crédito rural via programas públicos, como visto anteriormente. 
Enquanto algumas associações apresentavam um leque de ações e agendas, com alguma continuidade, a maioria das formadas unicamente visando ao crédito, sob influência das entidades sindicais, pareciam meramente formais. Mantinham as obrigações burocráticas de registro dos estatutos e pagamento das taxas anuais, enquanto esperavam a liberação ou a renegociação dos financiamentos. Essa situação parecia mais comum entre os grupos de pescadores, pois muitas vezes as associações tinham o nome de uma localidade ou bairro mas, na prática, reuniam membros de origens diversas que se tinham juntado apenas para compor o número mínimo de candidatos necessários à formulação de um plano de crédito. Vale notar que os pescadores são móveis, pela característica de sua atividade. Na costa do Pará, em particular, chegam a se deslocar até as costas dos estados vizinhos, Maranhão e Amapá.

Por outro lado, como apontado nos estudos de Lima (2001) e Silva (2006), embora sob outro prisma, as interações entre os grupos sociais locais e os parceiros remetem para o possível controle, ou mesmo monopólio, de canais de recursos; era o caso de políticos, partidos e organizações com poder em determinadas esferas. Os dados igualmente chamam a atenção para a importância de se considerarem as trajetórias pelas quais se constituem os grupos locais para agir coletivamente. São legados que, muitas vezes, pré-determinam parceiros e agendas, embora não se possa falar aqui de determinação rígida pela própria natureza dos contextos interativos. Vale lembrar, a esse respeito, o argumento de Degenne e Forsé (2004, p. 7) quanto ao "determinismo fraco" das estruturas de redes sociais: indivíduos e grupos entram em estruturas de relações pré-definidas, por exemplo quando se associam a um clube ou aderem a uma organização, mas as relações que emergem (e não emergem), afetam por seu turno aquela estrutura.

Assim, por exemplo, dentre as associações de agricultores em um dos municípios, Bragança, no extremo nordeste do Estado, que tinham um pequeno número de contatos e centradas na demanda e administração dos financiamentos para agricultura familiar, cinco haviam iniciado plantios coletivos para angariar fundos que aliviassem os agricultores no início dos plantios e evitassem ter de vender o produto adiantado ao intermediário. Iniciativas similares foram encontradas em duas associações de pescadores que haviam instituído a prática de os pescadores destinarem parte das capturas para venda na localidade, sob a responsabilidade da direção da associação. Enquanto uma ainda continuava a experiência no momento da pesquisa, a outra a tinha abandonado após muitos problemas de desconfiança 
quanto ao uso dos recursos, na opinião do dirigente de então. Os entrevistados reconheciam todos a limitação de conhecimentos locais em matéria de gestão.

A análise dos laços sociais entre as associações e seus contatos indicava, ademais, a prevalência de ligações verticais, isto é, tipicamente, associação local, associações da vizinhança, órgão do executivo municipal e sindicato. Não se percebiam contatos cruzados, entre grupos e municipalidades diversas. Não se tinham constituído fóruns que facilitassem a comunicação. Embora não se possa dizer a priori se e em que medida tais contatos cruzados seriam úteis, a coincidência de problemas, demandas e interesses sugere que sim.

A organização de associações de grupos camponeses para captar recursos públicos, em tese uma expressão de capital social nas localidades rurais, não conduzia de per se à capacidade de interferir nas ações do Estado e de determinados parceiros mais bem posicionados na estrutura de poder político e econômico. A título de ilustração, reclamava-se com muita freqüência da inflexibilidade dos processos de financiamento, tanto dos tipos de bens que podiam ser financiados quanto dos cronogramas de reembolso, indicando ausência de diálogo.

Como ressaltaram autores em outros contextos, os contatos observados reproduziam uma "tradição" clientelística nas relações entre Estado e sociedade na região. É o que se verificava, por exemplo, nos dados sobre a quem os dirigentes recorriam em momento de necessidade, ou a quem prestavam auxílio. Essas relações foram classificadas na rubrica 'favor', expressas na Figura 3, que representa quatro componentes nessa trama de relações. Favores incluíam principalmente doações ou empréstimo de dinheiro ou objetos, conselhos, auxílio na preparação do estatuto, transporte de pessoas em necessidade e pedidos para resolução de problemas na localidade. 


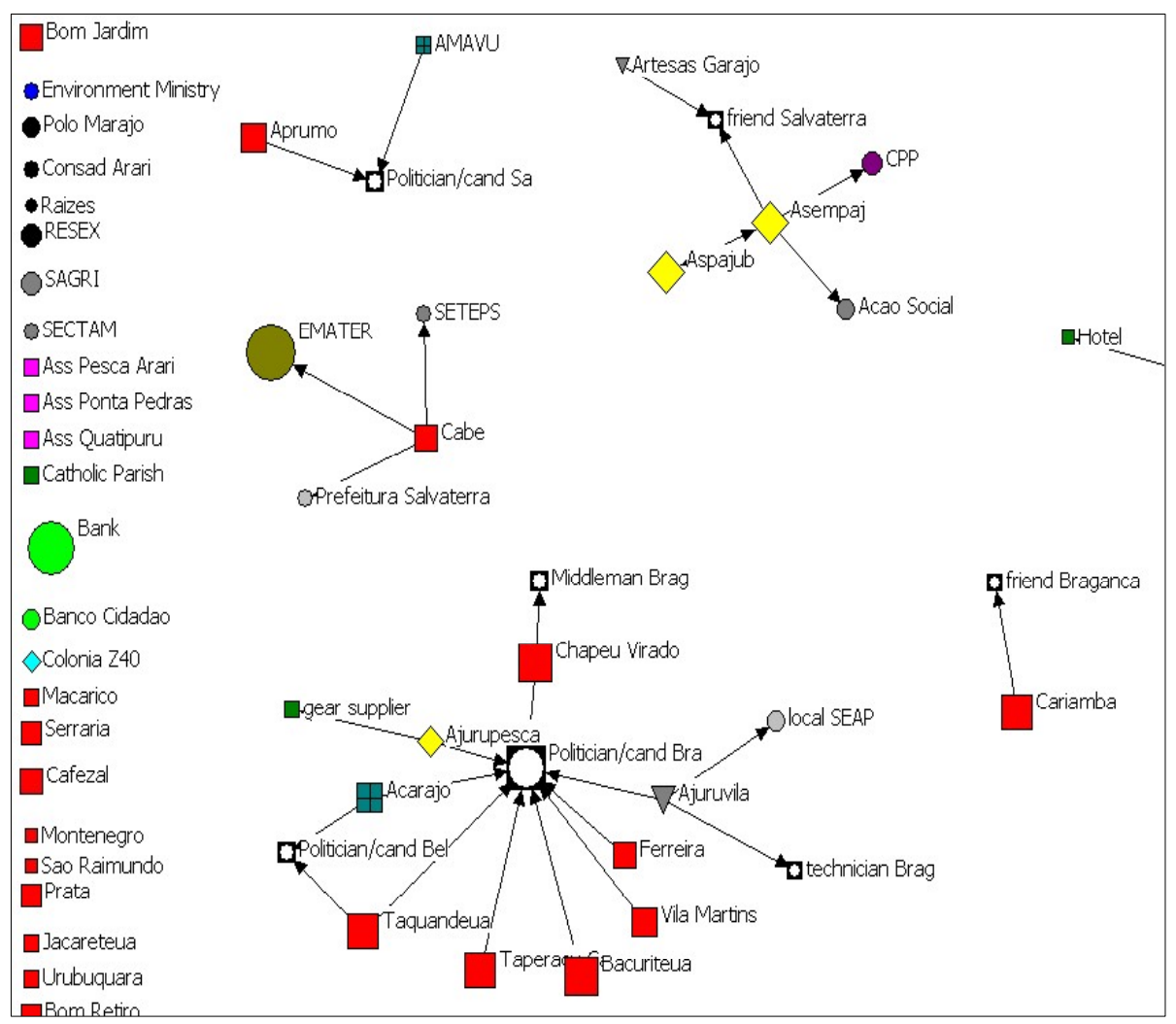

Figura 3. Esquema das relações de favor apontadas por líderes de associações rurais no nordeste do Pará (2005)

Uma primeira constatação refere-se ao pequeno número de envolvidos em relações de favor: cerca de $10 \%$ do total indicado na Figura 1. Em primeiro lugar, isso se deve ao fato de que, como visto antes, muitos elos da rede total eram instituições desenvolvendo programas ou ações de cunho mais formal, ou referiam-se a ligações funcionais, não escolhidas. Não se exclui, por outro lado, que relações de favor esporádicas estejam sub-representadas, por exemplo, ajuda mútua entre membros de associações da vizinhança. Mas, descontados esses fatores, permanece a pouca expressão numérica desse tipo de trocas e a posição destacada de uma categoria de provedores.

A centralidade dos políticos (eleitos ou candidatos) é evidente no maior componente dessa rede, na parte inferior da Figura 3. Políticos eram personagens chave quando se pleiteava serviços ou equipamentos para a localidade e, com freqüência, para ajudar em uma situação de doença de algum associado e para custear o registro de documentos. Um padrão diferente de relações, mais horizontal, era visível no caso das associações de pescadores representadas no canto superior direito da figura, que indicaram uma a outra como fonte de ajuda. Nesse caso, tratou-se do apoio prestado pela associação mais antiga na criação da mais nova, através de visitas e orientações de seu dirigente, informações sobre 
oportunidades de financiamento e, algumas vezes, empréstimo de pequenas somas. Uma também apontou um amigo, uma ONG de apoio a pescadores artesanais e um órgão de assistência social do governo municipal. As trajetórias dessas últimas associações ligavam-se, em parte, à experiência prévia dos líderes em atividades comunitárias estimuladas pela I greja Católica e, mais recentemente, pela Pastoral dos Pescadores, uma das chamadas pastorais sociais católicas. Mais recentemente, um dos líderes havia entrado em um partido político de esquerda.

\section{Conclusões e questões}

Nas condições vigentes e na ausência das "outras formas de capital", conexões sociais revestiam-se de especial importância para as associações alcançarem seus objetivos. Porém, observou-se que suas conexões não eram suficientes para se sobreporem às restrições dos contextos locais. Assim, a rede de contatos tendia a reproduzir as vulnerabilidades dos grupos de associados e de suas comunidades. Eles estavam direta ou indiretamente expostos a muitos tipos de contatos, mas o acesso efetivo não era uniforme.

As áreas da rede com maior diversidade de relações eram, precisamente, aquelas que se relacionavam a territórios especiais; no caso deste estudo, tratava-se das inseridas em unidades de conservação ambiental e seu entorno e das comunidades quilombolas. Para elas convergem, na atualidade, interesses e atores cujas conexões se estendem até o plano internacional.

Viu-se que nós periféricos eram portadores de informação "não redundante" ${ }^{5}$ e canais potenciais para contatos variados, oportunidades de participar em eventos, por vezes acesso a financiamentos alternativos para "pequenos projetos" de desenvolvimento local, ligações com ONGs e movimentos atuando em áreas de interesse correlato. Algumas associações e organizações estavam assegurando esses fluxos diversos na rede e, portanto, atuando como pontes (cf. Granovetter, 1982). Dentre elas, associações de pescadores, agricultores, mulheres e quilombolas representadas na Figura 2.

\footnotetext{
${ }^{5}$ Conforme o valor que Granovetter (1982) atribuiu aos 'laços fracos' como fontes de informação nova, circulante em outras esferas sociais e, sob uma perspectiva mais ampla, de promoção de integração societária.
} 
Constatou-se que barreiras concretas de comunicação reduziam a habilidade da rede em difundir os eventuais benefícios desses fluxos. A generalizada escassez de meios para viagens de líderes e associados, seja em termos materiais, tempo ou infra-estrutura de apoio, era uma barreira evidente nesse sentido. Poucas iniciativas, inclusive do poder público, visavam as restrições na comunicação.

Por outro lado, também ficou clara a necessidade de se considerarem os sentidos dos fluxos de comunicação entre parceiros em posições desiguais, o que indicaria a qualidade de capital social dessa rede do ponto de vista dos grupos locais. De fato, via-se as associações com pouca ou nenhuma interferência na definição das agendas dos 'nós' com maior poder. Isso era evidente no caso dos financiamentos oficiais, concedidos segundo regras e formatos predefinidos, sem margem de flexibilidade. Manifestava-se, também, nos poucos programas de fomento a pequenos produtores levados a efeito por governos municipais e por algumas ONGs atuando com linhas de financiamento às quais associações tinham acesso.

Segue-se que, para que os recursos possam ser acessados de maneira eficaz, mais do que associações recebedoras de "pacotes de desenvolvimento", fixados alhures, os membros poderiam conhecer e partilhar experiências diversificadas e inovações na lida com problemas comuns aos grupos nos seus vários territórios. Dentre os problemas, destacavam-se a dependência aos intermediários na comercialização dos produtos, as restrições de crédito e as pesadas pressões ambientais.

Portanto, as associações não estavam explorando o rol de recursos imersos na rede ou potencialmente disponíveis por meio das diferentes organizações e movimentos sociais aos quais se vinculavam, quer por obrigação ou necessidade, quer por estratégias e oportunidades que se apresentavam.

Na perspectiva de um padrão de desenvolvimento com efetiva participação das associações, o conhecimento das estruturas dos contatos aponta para a utilidade de intervenções sobre o ambiente das interações, para ampliar e diversificar seus canais. Uma possibilidade imediata a considerar é a de se proverem apoios específicos àquelas associações que assumiam os esforços de "fazer as pontes" e que contribuíam para a geração de capital social através de seus contatos... freqüentemente com altos custos pessoais e familiares para os líderes e sócios mais ativos. A idéia é facilitar a construção de laços de tipo horizontal entre associações e grupos similares com interesses próximos, mas que se encontram distantes no espaço físico e social. Esses apoios específicos não poderiam prescindir de mecanismos concretos de interação para o conjunto de organizações locais, como 
por exemplo fóruns organizados pelo poder público, de participação livre e independente de vinculações partidárias e políticas. Como dito acima, os dados mostraram que dirigentes e associados tinham dificuldades para se deslocar não só por falta de recursos financeiros ou de infra-estrutura, mas também de tempo.

Uma hipótese a ser testada é a de que interferências dessa natureza, focalizando os entraves à comunicação e ao diálogo para associações locais, teriam como efeito potencializar a qualidade de sua rede de relações em ser fonte de capital social. Em outras palavras, promoveriam a autonomia relativa da rede sobre o meio social, ao invés de reproduzi-lo, como prevalecia no caso em estudo.

Por certo, tal resultado requer bem mais que esforços para desenvolver as capacidades relacionais. Requer também, como se viu, atenção às condições sociais herdadas e seus efeitos diferenciais sobre as organizações, seus parceiros e modalidades de intercâmbio. De um lado, considerar como novas associações se coadunam, ou não, com padrões costumeiros de ação coletiva nas comunidades rurais, se há imposição de padrões, sobreposição ou conflitos de interesses. De outro, o conjunto de fatores econômicos, políticos e ambientais que restringem não só as capacidades relacionais, como reforçam a submissão dos locais a agentes externos e sua posição subalterna em redes econômicas e políticas e que, no limite, ameaçam a permanência das categorias sociais chamadas a se associar.

\section{Referências}

Avritzer, Leonardo. (1997). “Um desenho institucional do novo associativismo", Lua Nova, n. 39.

Beall, Jo. (2001). "Valuing social resources or capitalizing on them? Limits to propoor governance in nine cities of the South", International Planning Studies. Vol. 6 (4), p. 357-375.

Borgatti, Steve, Everett, Martin and Freeman, L. C. (2002). Ucinet for Windows: software for social network analysis. Harvard, MA: Analytic Tehnologies.

Bourdieu, Pierre. (1986). "The forms of capital". In: Richardson, John G. (ed.) Handbook of theory and research for the sociology of education. New York, Greenwood Press, p. 241-258.

Brasil/MIN/MMA. (2004). Plano Amazônia Sustentável. Brasília, Ministério da Integraçao Nacional e Ministério do Meio Ambiente. 
Cleaver, Frances. (2005). "The inequality of social capital and the reproduction of chronic poverty", World Development, v. 33, n. 6, pp. 893-906.

Castells, Manuel. (2000). A sociedade em rede. São Paulo, Paz e Terra.

Coleman James S. (1988). "Social capital in the creation of human capital", The American Journal of Sociology. Vol. 94, Supplement: Organizations and Institutions. Sociological and Economic Approaches to the Analysis of Social Structure.

Costa, Sérgio. (1999). “Esfera pública e as mediações entre cultura e política: para uma leitura sociológica da democratização brasileira", TRAVESSIAS, Revista da Associação de Ciências Sociais e Humanas em Língua Portuguesa. n. 1, p. 27-72.

Degenne, Alain e Forsé, Michel. (1999). Introducing social networks. London, SAGE.

D’Incao, Maria Conceição. (2000). “Clientelismo e democracia na organização dos agricultores familiares da microrregião de Marabá: a Associação dos Pequenos Agricultores da Consulta", Agricultura Familiar: Pesquisa, Formação e Desenvolvimento, Belém: NEAF, v. 1 (2), p. 113-139.

Fontes, Breno Augusto e Eichner, Klaus. (2004). “A formação do capital social em uma comunidade de baixa renda", Redes. Revista Hispana para el Análisis de Redes Sociales, 7 \#2 Consulta [14-03-2006] em <http://revista-redes.rediris.es>.

Esterci, Neide; Lima, Deborah e Lena, Philippe. (2002). “Diversidade sociocultural e políticas ambientais na Amazônia: o cenário contemporâneo", Boletim Rede Amazônia. 1, p. 3-8.

Granovetter, Mark. (1974). Getting a job; a study of contacts and careers. Cambridge, Harvard University Press.

Granovetter, Mark. (1982). "The strength of weak ties: a network theory revisited". In: Marsden, Peter V. e Lin, Nan. Social structure and network analysis. Beverly Hills, SAGE. p. 105-130.

Granovetter, Mark. (2004). "Economic action and social structure: the problem of embeddedness". In: Dobbin, Frank (ed.). The new economic sociology; a reader. New Jersey, Princeton University Press, p.245-272. 
Hébette, Jean. (2002). "Reprodução social e participação política na fronteira agrícola paraense: o caso da Transamazônica". In: Hebette, Jean, Magalhães, Sônia B. e Maneschy, Maria Cristina. (organizadores). No mar, nos rios e na fronteira: faces do campesinato no Pará. Belém. EDUFPA, p. 233-273.

Kerstenetzky, Célia Lessa. (2003). "Sobre associativismo, desigualdades e democracia", Revista Brasileira de Ciências Sociais, out., v. 18, p. 131-142.

Lima, Jacob C. (2001). "Teoria do capital social na análise de políticas públicas", Politica \& Trabalho, 17. Set., p. 46-63.

Lin, Nan. (2001). Social capital, a theory of social structure and action. Cambridge University Press.

Medeiros, Leonilde Servolo de e Leite, Sérgio (Orgs). (1999). A formação dos assentamentos rurais no Brasil. Processos sociais e políticas públicas. Porto Alegre: UFRGS; Rio de Janeiro: CPDA.

Moreira, Edma Silva. (2002). Tradição em tempos de modernidade: reprodução social numa comunidade varzeira do rio Xingu/PA. 2002. 122 f. Dissertação (Mestrado em Sociologia) - Universidade Federal do Pará. Departamento de Sociologia, Belém.

Murdoch, Jonathan. (2000). "Networks, a new pardigm of rural development?", J ournal of Rural Studies, 16: 407-419.

Portes, Alejandro. (1998). "Social capital: its origins and applications in modern Sociology", Annual Review of Sociology, 24: 1-24.

Putnam, Robert. (2002). Bowling alone; the collapse and revival of American community. New York, Simon \& Schuster.

Putnam, Robert. (2005). Comunidade e democracia; a experiência da Itália moderna. Rio de Janeiro, FGV.

Silva, Marcelo Kunrath (2006). "Sociedade Civil e construção democrática: do maniqueísmo essencialista à abordagem relacional", Sociologias. Porto Alegre, ano 8, n. 16, jul/dez, p. 156-179. 
Sine-Pará. Secretaria Executiva de Trabalho e Promoção Social. (2003). A pesca artesanal no Pará: perfil sócio-econômico e organizacional dos pescadores filiados às colonias. Belém, SETEPS/SINE-PA.

Theiss-Morse e Hibbing, John. (2005). "Citizenship and civic engagement", Annu. Rev. Polit. Sci. 8: 227-49.

Tura, Letícia Rangel. (2002). “Notas introdutórias sobre os fundos constitucionais de financiamento e sua configuração na Região Norte". In: Tura, Letícia Rangel; Costa, Francisco de Assis. Campesinato e Estado na Amazônia. I mpactos do FNO no Pará. Brasília: Brasília J urídica; FASE, p. 29-46.

Tura, Letícia Rangel. (2002). "Atores sociais e o suporte institucional dos projetos do FNO-Especial". In: Tura, Letícia Rangel; Costa, Francisco de Assis. Campesinato e Estado na Amazônia. Impactos do FNO no Pará. Brasília: Brasília Jurídica; FASE, p. 271-321.

Woolcock, Michael and Narayan, Deepa. (2000). "Social capital: implications for development theory, research and policy", The World Bank Researcher Observer. Aug., 15 (2), p. 225-247. 